\title{
Application of multivariate statistical techniques for investigating climate change and anthropogenic effects on surface water quality assessment: case study of Zohreh river, Hendijan, Iran
}

\author{
Jalal Valiallahi $^{1}$ D . Saideh Khaffaf Roudy ${ }^{1}$
}

Received: 21 November 2017 / Accepted: 25 March 2021 / Published online: 29 May 2021

(c) The Author(s) 2021

\begin{abstract}
In the present study, evaluation of spatial variations and interpretation of Zohrehh River water quality data were made by using multivariate analytical techniques including factor analysis and cluster analysis also the Arc GIS® software was used. The research method was formulated to achieve objectives herein, including field observation, numerical modeling, and laboratory analyses. The results showed that dataset consisted of 11,250 observations of seven-year monitoring program (measurement of 15 variables at 3 main stations from April 2010 to March 2017). Factor analysis with principal component analysis extraction of the dataset yielded seven varactors contributing to $82 \%$ of total variance and evaluated the incidence of each varactor on the total variance. The results of cluster analysis became complete with t-test and made water quality comparison between two clusters possible. Results of factor analysis were employed to facilitate t-test analysis. The t-test revealed the significant difference in a confidence interval of 95\% between the mean of calculated varactors 1, 2, 6 and 7 between two clusters, but there was no significant difference in the mean of other varactors 3, 4 and 5 between two groups. The result shows the effect of agricultural fertilizers on stations located at downstream of the ASK dam.
\end{abstract}

Keywords Surface water quality $\cdot$ Multivariate statistical techniques $\cdot$ Factor analysis $\cdot$ Cluster analysis $\cdot$ Zohreh river

\section{Introduction}

Observational records and climate projections provide abundant evidence that freshwater resources are vulnerable and have the potential to be strongly impacted by climate change, with wide-ranging consequences for human societies and ecosystems (Bates et al. 2008). The Zohreh river basin is one of the important arias that nowadays is affected by anthropogenic and climate change.

"Zohreh basin with the area of about $16,000 \mathrm{~km}^{2}$ is located between $49^{\circ}, 27^{\prime}$ to $52^{\circ}, 19^{\prime} \mathrm{E}$ longitudes and $29^{\circ}$, $46^{\prime}$ to $30^{\circ}, 59^{\prime} \mathrm{N}$ latitudes and it is one of the important basins in Iran. Since the Zohreh basin is located in Fars, Kohgiluyeh and Boyer-Ahmad and Khuzestan provinces, its

Jalal Valiallahi

jvaliallahi@yahoo.com; iraneesd@yahoo.com

Saideh Khaffaf Roudy

saideh_khaffaf@yhoo.com

1 Department of Environmental Sciences, Shahid Rajaee Teacher Training University, Tehran, Iran integrated environmental management is facing a serious challenge. The broad consumption of river water and the probability of water pollution made essential the studying of water quality and removing the pollutants (Manshouri et al. 2011). In addition, surface water is highly prone to point and non-point pollutions due to its easy accessibility for disposal of wastewaters, difficulty with its protection, it's being uncovered, and its high flow velocity. "Surface water is influenced by natural processes (precipitation, erosion, weathering of crustal materials) and anthropogenic effects (urban, industrial, and agricultural activities and increasing consumption of water resources)" (Zhang et al. 2008). "Anthropogenic effects have the vast affinity to hasten natural phenomes that affect water quality" (Yidanaa et al. 2008). "Water quality denotes to the physical, biological and chemical aspects of water" (Wanga et al. 2005).

"Discharges from municipals and industries are considered as a point and constant polluting source, while surface runoff is a seasonal phenomenon and non-point source due to its characteristics that are highly influenced by climate and seasonal changes" (Han et al. 2009; Shrestha and Kazama 2007). 
Surface waters have heterogeneity in space and time. Temporal and spatial changes both in natural process and anthropogenic influences cause spatiotemporal variations in water quality parameters; therefore, reliable and regular monitoring programs reflecting the variations have to be set. In Iran, governmental companies have carried out water quality monitoring programs, but many of those monitoring programs contain large datasets. A particular problem in the case of water quality monitoring is the complexity associated with analyzing a large number of measured variables. The datasets contain rich information about the behavior of the water resources.

High temperatures and extreme rainfall, including floods and droughts, affect the quality of water and change many forms of water pollution, including sediment, nutrients, and organic soluble carbon in water (Bates et al. 2008).

"Classification, modeling, and interpretation of monitored data are the most important steps in the assessment of water quality" (Iscen et al. 2008). "Water quality monitoring has one of the highest priorities in surface water protection policy. Multivariate statistical methods have been used successfully in hydrochemistry for many years. Using multivariate statistical methods help to better understand water quality in the interpretation of complex datasets (Zhang et al. 2009). "Multivariate statistical methods are widely used in various environmental measurements.

They have been presented as appropriate tools in water quality assessment, identification of pollution sources/factors and understanding temporal/spatial variations in water quality for effective river water quality management" (Singh et al. 2005). They may be particularly useful when there is a large volume of experimental results and sometimes they provide insight into the multidimensional patterns in the data that would be overlooked with uni variety analyses" (Shtangeeva et al. 2009). The multivariate methods applied in water quality analyses are cluster analysis (CA), discriminant analysis (DA), factor analysis (FA), principal component analysis (PCA), and exploratory factor analysis (EFA).

"Factor analysis was particularly useful for considering several related random environmental variables simultaneously, and so identification of a new, smaller set of uncorrelated variables that accounted for a large proportion of the total variance in the original variables"(Wang et al. 2007). Varimax factor rotation method rotates the axis such that the two vertices remain 90 degrees (perpendicular) to each other and assumes uncorrelated factors (also referred to as orthogonal rotation). "Cluster analysis (first used by Tryon 1939) classifies objects so that each object can be similar to the others in the cluster with respect to a predetermined selection criterion. The clusters of objects must be homogeneous (within the cluster) and not very solid (between clusters) "(Varol and Sen 2008).
The goal is to compare the data of a similar (or related) group to one another and different from (or unrelated) data in other groups, the greater the similarity (or homogeneity) within a group, and the greater the difference between groups, the better or more distinct the clustering. The component analysis and exploratory factor analysis are a multivariate statistical technique used to identify the important components or factors that explain more of the variance of the system. To reduce the number of variables to a small number of indicators (that is, the main components or factors are designed to reduce the relationships existing in the original data "(Ouyang 2005). PCA is a declining variable technique and is used when the variables overlap strongly. This method reduces the number of observed variables to a number of major components, which is more than the variance of observed variables. The total value of the variance in the PCA is equal to the number of variables examined. In PCA, the observed variables are standardized, for example, the mean $=0$, standard deviation $=1$, the matrix diameter is 1. The value of the described variance is equal to the matrix trace (sum of the matrices decomposed correlation diameters). The number of extracted components is equal to the number of variables observed in the analysis. The first major component identified is the most variance between data. The second component is identified for the second level of variance in the data and does not match the first major component, and so on. The accounting components are kept for the maximum variance, while other accounting components are not kept for the importance of the variance value. "Specific values represent the amount of variance explained by each component. The special features of the weights are used to calculate the components of the components." (Diana 1999).

\section{Materials and methods}

The purpose of this study is to accurately assess water quality status in the Zohreh river (Figs. 1,2). To archiving this purpose, a multivariate statistical technique, PCA and hierarchical cluster analysis, factor analysis (FA) have been used to assess the spatial variability of water quality parameters and discriminate the relative magnitude of anthropogenic influences on the river water quality in the Zohreh river basin located in southwest Iran in Khuzestan province.

The Zohreh river is the only one provider of drinking water, agriculture and industry in the region. So, changing of quality or fluctuations of water criteria in this river is very important. In this study, after preparing samples and performing experiments required, the database of water quality was prepared.

In order to obtain the information required about Zohreh river, three main sampling stations were selected. Selected stations are Chambostan, Dehmolla, Shiri, respectively. 


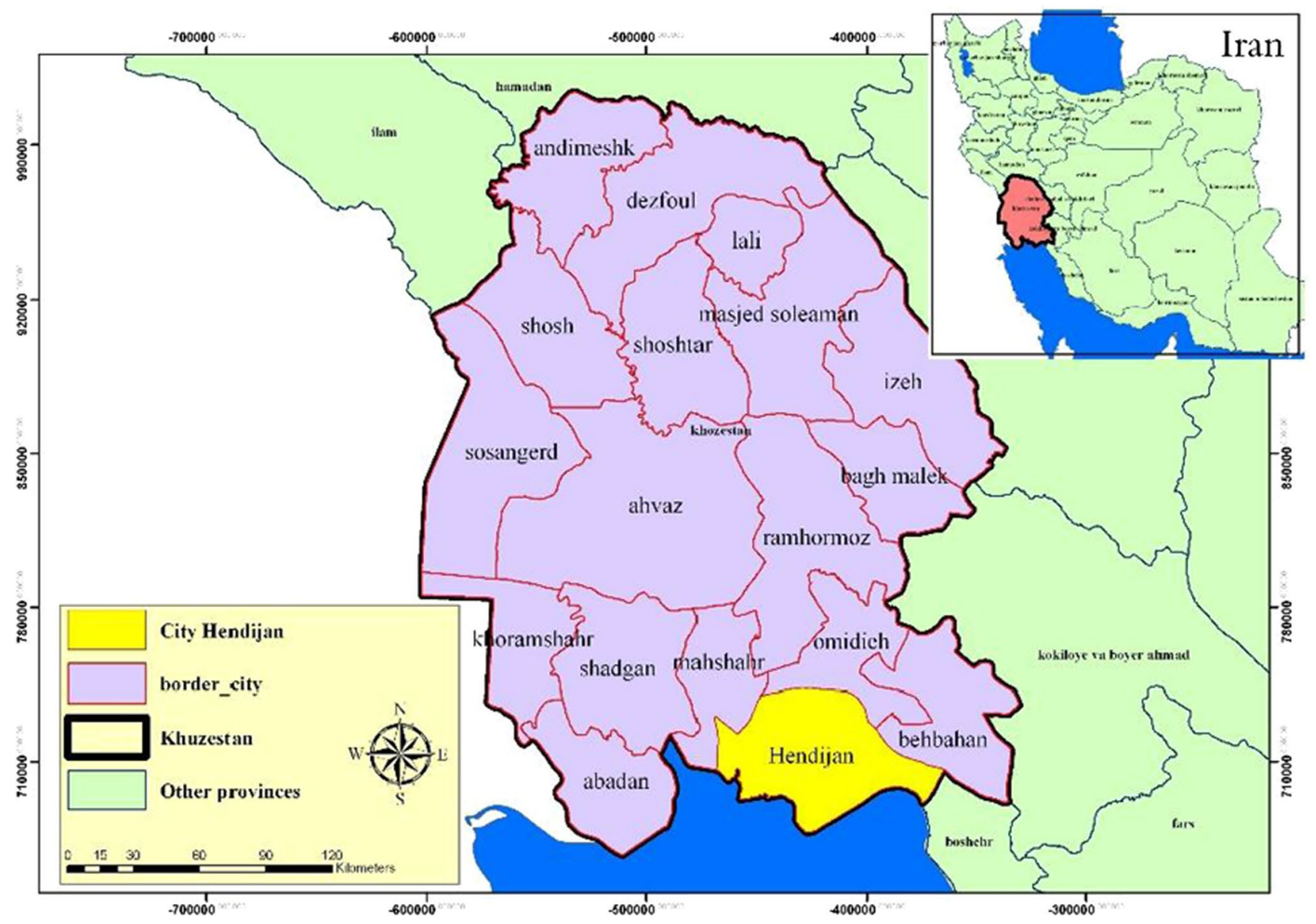

Fig. 1 Khuzestan south west of Iran and Hendijan city

The data for water quality of these stations from 2010 to 2017 for the various parameters of water quality dataset were obtained from Khuzestan Province Regional Water Agency. This agency collects surface and groundwater samples monthly and analyzes them using standard methods for electrical conductivity (EC), total dissolved solids (TDS), $\mathrm{pH}$, total hardness $(\mathrm{TH})$, major cations as calcium $(\mathrm{Ca} 2+)$, magnesium $(\mathrm{Mg} 2+)$, sodium $(\mathrm{Na}+)$ and potassium $(\mathrm{K}+)$ and major anions as chloride ( $\mathrm{Cl}-$ ) and sulphate (SO42-), bicarbonate (HCO3-) temperature ( $\mathrm{T})$ in addition to sampling locations latitude and longitude. The data were extracted from the monitoring program conducted by Khuzestan water and wastewater company and include samplings along the Zohreh river during a seven years' period (from April 2010 to March 2017); this program provided a dataset of 3 main stations (Figs. 1,2) in which the samplings were carried out monthly.

Dataset consisted of 11,250 observations of seven-year monitoring program (measurement of 15 variables at 3 main stations from April 2010 to March 2017). Among these data, descriptive statistics analyzing carried out on 6 water quality parameter TDS, EC, pH, Hco3, $\mathrm{Ca}$ and $\mathrm{Mg}$, among a total number of 729 selected sample from three main stations in Zohreh river.

Data from laboratory results were interred to the statistical software SPSS version 23 and also were transferred to Arc GIS ver. 10. Information provided including lab results and statistical calculation was transferred to the map layer. The objective of the study is to extract information about; the similarities or dissimilarities between monitoring sites, identification the influence of possible sources (natural and anthropogenic) on water quality parameters of the Zohreh river.

\section{Study aria Zohreh river}

Hendijan is a historical city of Iran over 3000 years old, in the south-eastern Khuzestan province and $75 \mathrm{~km}$ southeast of Mahshahr city. The Hendijan (Zohreh) river divided Hendijan city into two halves from North to South. There are a number of different parameters like discharge which affect water quality and conditions. Typically, water quality is expected to improve by the increase in discharge and significantly influenced by the runoff entering the river system. 


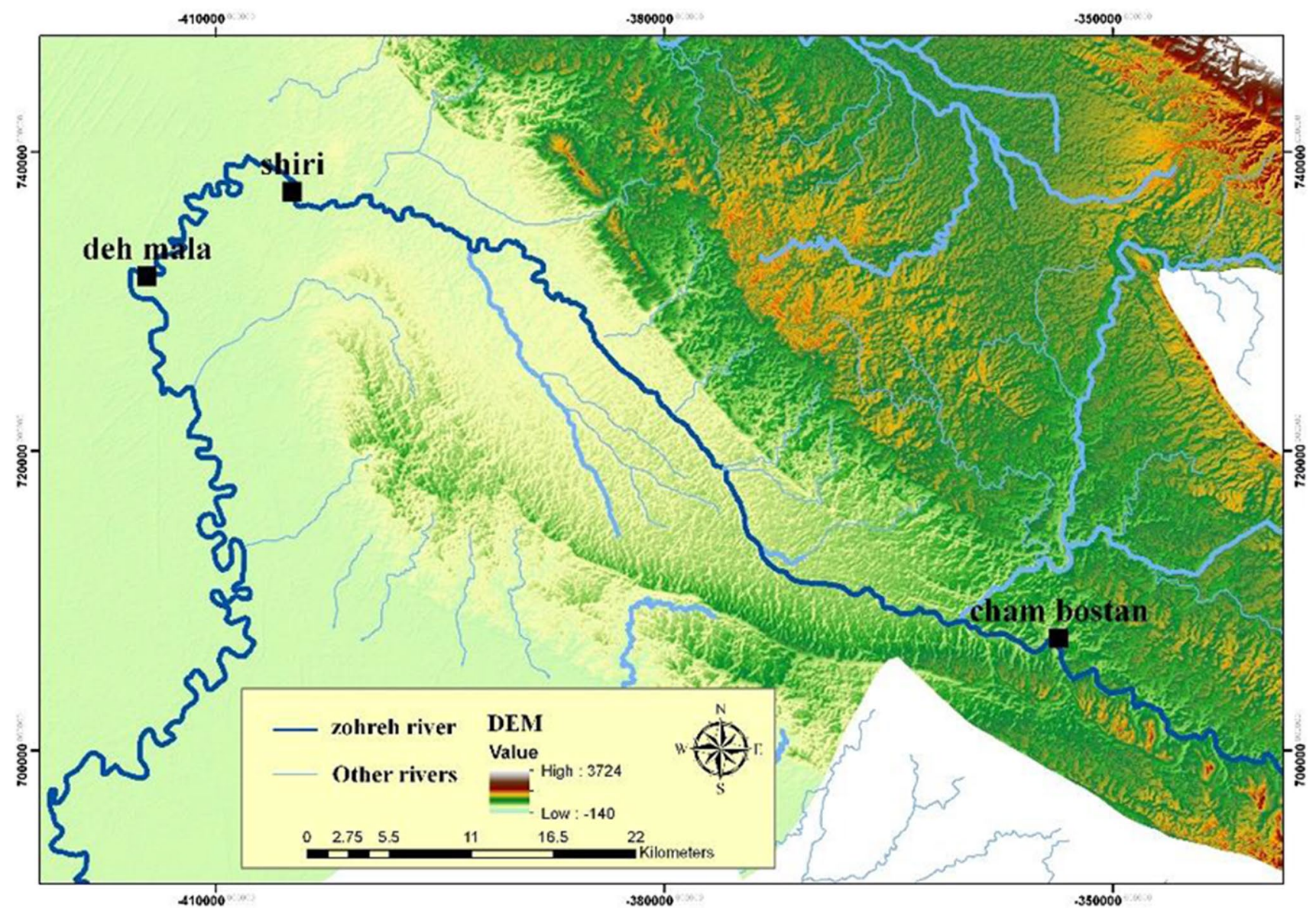

Fig. 2 Dem of Hendijan city and three main stations, from right to left, Cham Bostan, Shiri and Dehmola along the Zohreh river

\section{Tables and graphs}

The present study was conducted over a relatively long range of Zohreh river about $275 \mathrm{~km}$ over a seven-year long period of time and using qualitative parameters values at 3 stations.

\section{Factor analysis}

The results of Table 1. indicate the highest value of EC (2570) and lowest values (101.80) also descriptive statistics analyzing of 6 water quality parameter TDS, EC, pH, Hco3, $\mathrm{Ca}$ and $\mathrm{Mg}$, from a total number of 729 sample at three main stations in Zohreh river (Tables 2, 3).

For involving PCA method, a combination matrix was offered (Table 4). Components that covered a small part of the changes in dataset were excluded. Finally, 2 main factors, the main variables in each component were extracted. Also, share obtained was presented in the Table 5 .

At the next step, the correlation coefficients between the factors specified in Table 1 were applied to all data in all station. Correlation matrix variables were examined and showed a strong correlation between the variables. In this
Table 1 descriptive statistics of total number of 729 water sample analyzing of 6 water quality parameter TDS, EC, pH, Hco3, $\mathrm{Ca}$ and $\mathrm{Mg}$, in Zohreh river

\begin{tabular}{lllrrl}
\hline & $N$ & Minimum & Maximum & Mean & $\begin{array}{l}\text { Std. } \\
\text { Deviation }\end{array}$ \\
\hline TDS & 729 & 2.09 & 1670.50 & 215.1837 & 92.90130 \\
EC & 729 & 101.80 & 2570.00 & 337.3466 & 143.75352 \\
PH & 729 & 5.51 & 8.60 & 7.8391 & .31378 \\
$\mathrm{Hco} 3$ & 729 & .50 & 5.77 & 2.4611 & .52871 \\
$\mathrm{Ca}$ & 729 & 3.06 & 30.00 & 8.2146 & 3.13451 \\
$\mathrm{Mg}$ & 729 & .80 & 43.24 & 3.6202 & 2.41219 \\
Valid $N$ & 729 & & & & \\
$\quad$ (listwise) & & & & & \\
\hline
\end{tabular}

way, Table 2 was generated. The correlation that results are summarized in Table 2 (mathematical and statistical computations). As showed in Table 2, high relationships between factors are indicated by two stars, so we can say that correlation between these parameters has correlated at $99 \%$ confidence. 
Table 2 Correlation matrix between 6 main water quality parameter in Zohereh river, high relationships between factors are shown by two stars

\begin{tabular}{|c|c|c|c|c|c|c|}
\hline Correlations & TDS & $\mathrm{Ec}$ & $\mathrm{PH}$ & Hco3 & $\mathrm{Ca}$ & $\mathrm{mg}$ \\
\hline \multicolumn{7}{|l|}{ TDS } \\
\hline Pearson correlation & 1 & & & & & \\
\hline \multicolumn{7}{|l|}{ Sig. (2-tailed) } \\
\hline$N$ & 729 & & & & & \\
\hline \multicolumn{7}{|l|}{ EC } \\
\hline Pearson correlation & $.979^{* * *}$ & 1 & & & & \\
\hline Sig. (2-tailed) & .000 & & & & & \\
\hline$N$ & 729 & 729 & & & & \\
\hline \multicolumn{7}{|l|}{$\mathrm{pH}$} \\
\hline Pearson correlation & $-.149^{* *}$ & $-.134^{* *}$ & 1 & & & \\
\hline Sig. (2-tailed) & .000 & .000 & & & & \\
\hline$N$ & 729 & 729 & 729 & & & \\
\hline \multicolumn{7}{|l|}{ Hco3 } \\
\hline Pearson correlation & $.268^{* * *}$ & $.261^{* * *}$ & $-.249^{* *}$ & 1 & & \\
\hline Sig. (2-tailed) & .000 & .000 & .000 & & & \\
\hline$N$ & 729 & 729 & 729 & 729 & & \\
\hline \multicolumn{7}{|l|}{$\mathrm{Ca}$} \\
\hline Pearson correlation & $.469^{* *}$ & $.418^{* *}$ & $-.284^{* *}$ & $.226^{* *}$ & 1 & \\
\hline Sig. (2-tailed) & .000 & .000 & .000 & .000 & & \\
\hline$N$ & 729 & 729 & 729 & 729 & 729 & \\
\hline \multicolumn{7}{|l|}{$\mathrm{Mg}$} \\
\hline Pearson correlation & $.777^{* *}$ & $.783^{* *}$ & $-.138^{* *}$ & $.274^{* *}$ & $.433^{* *}$ & 1 \\
\hline Sig. (2-tailed) & .000 & .000 & .000 & .000 & .000 & \\
\hline$N$ & 729 & 729 & 729 & 729 & 729 & 729 \\
\hline
\end{tabular}

${ }^{* *}$ Correlation is significant at the .01 level (2-tailed)
Table $3 \mathrm{KMO}$ test result

Kaiser-Meyer-Olkin Measure of Sampling Adequacy

.724

Bartlett's Test of Sphericity

Approx. Chi-Square

$d f$

15

Sig

.000
Table 5 Extraction method: principal component analysis

\begin{tabular}{lll}
\cline { 2 - 3 } & Initial & Extraction \\
\hline TDS & 1.000 & .934 \\
Ec & 1.000 & .928 \\
$\mathrm{pH}$ & 1.000 & .723 \\
$\mathrm{Hco} 3$ & 1.000 & .462 \\
$\mathrm{Ca}$ & 1.000 & .474 \\
$\mathrm{mg}$ & 1.000 & .791 \\
\hline
\end{tabular}

In the third step, rotated component matrix was applied, and the results are shown in Table 6. To extract these components from within the main parameters of water quality, from time to time varimax rotated factor was used. Accordingly, each component parameter which the highest load factor (positive or negative) that was the best representative of that component is described. Based on PCA, the data were classified into 2 groups.

The result of Table 6 shows all the variables fall into two groups and variables TDS, EC and $\mathrm{mg}$ in one group of variables $\mathrm{pH}, \mathrm{Hco} 3$ and $\mathrm{Ca}$ are other groups.
Extraction method: principal component analysis

Two component extracted 
Table 6 Rotated component matrix

\section{Cluster analysis}

The hierarchical cluster was used to implement this method. Initially, a proximity matrix was obtained according to Table 7.

The parameters in the two clusters are shown in Table 8.

According to this table and graph 4, TDS and EC at the bottom are in the first cluster parameters and parameters of $\mathrm{PH}, \mathrm{Hco} 3, \mathrm{Ca}$ and $\mathrm{Mg}$ were placed in the second cluster. And finally, dendrogram charts presented in Fig. 3.

\section{Results}

Factor analysis with principal component analysis extraction (PCA) method was investigated. PCA of the dataset resulted in seven principal components (PCs) with eigenvalues $>1$ accounting for almost $82 \%$ of total variance; the higher the eigenvalue, the more significant the corresponding component (Tables 2, 3).

Based on the results, all measured values for the Zohreh river indicate that the river's water at upstream can be used for drinking only by applying advanced refining.

In fact, over the course of this seven-year period, the decline in water quality, especially at the Shiri Station, has been highlighted.

In general, by evaluating of water quality trends in time series at the measuring stations, we find that river water and its pollutants are somehow balanced. In other words,
Table 8 The parameters in the two clusters membership

\begin{tabular}{ll}
\hline Case & 2 clusters \\
\hline 1: $\mathrm{TDS}$ & 1 \\
2: $\mathrm{EC}$ & 1 \\
3: $\mathrm{pH}$ & 2 \\
4: $\mathrm{HCO} 3$ & 2 \\
$5: \mathrm{Ca}$ & 2 \\
6: $\mathrm{Mg}$ & 2 \\
\hline
\end{tabular}

Dendrogram using Average Linkage (Between Groups) Rescaled Distance Cluster Combine

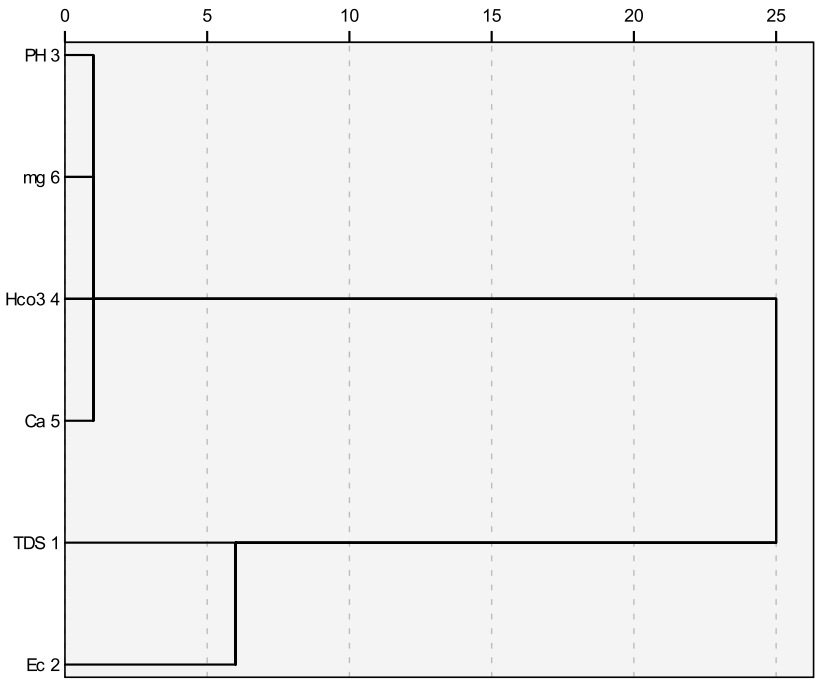

Fig. 3 Dendogram using average linkage between group

the volume of input pollutants has been proportional to river self-purification capacity.

Meanwhile, the water quality of the river varies in the various watery and various seasons.

Also, considering the results of the study, it can be concluded that most of the pollution of the Zohreh river is entering the Shiri Station, and the relative increase in the indicator at the station of Dehmola and Cham Boston
Table 7 Proximity matrix

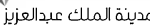
KACST́

\begin{tabular}{lllllll}
\hline Case & \multicolumn{5}{l}{ Squared euclidean distance } \\
\cline { 2 - 7 } & 1: TDS & 2: EC & 3: $\mathrm{pH}$ & 4: Hco3 & 5: Ca & 6: $\mathrm{Mg}$ \\
\hline 1: TDS & .000 & $279,880.240$ & $773,868.980$ & $799,599.543$ & $756,388.214$ & $782,119.235$ \\
2: $\mathrm{EC}$ & $279,880.240$ & .000 & $1,981,669.860$ & $2,022,720.617$ & $1,953,738.782$ & $1,994,818.333$ \\
3: $\mathrm{pH}$ & $773,868.980$ & $1,981,669.860$ & .000 & 223.059 & 157.552 & 42.811 \\
4: $\mathrm{Hco3}$ & $799,599.543$ & $2,022,720.617$ & 223.059 & .000 & 641.462 & 120.667 \\
5: $\mathrm{Ca}$ & $756,388.214$ & $1,953,738.782$ & 157.552 & 641.462 & .000 & 271.445 \\
6: $\mathrm{Mg}$ & $782,119.235$ & $1,994,818.333$ & 42.811 & 120.667 & 271.445 & .000 \\
\hline
\end{tabular}

This is a dissimilarity matrix 
indicates a decrease in the input rate of pollutants and the effectiveness of self-purification the river.

Bearing in mind water quality parameters of selected stations, the TDS situation has been inadequate in all three stations in recent years. In the comparison of this parameter at more polluted Shiri station with other station, it reviled that, this parameter is not related to the ASC dam construction near the station.

Although the amount of pollution in the winter is less than summer, during rainy months, and increasing of surface runoff from agricultural land and urban and rural wastewaters flow into the river, causing significant pollution at all stations.

The EC has gradually reached its maximum levels in different years at all three stations.

Which is higher at Shiri station compared to other stations. The reason for the high rate of this variable at this station can be attributed to the ASC dam construction, which is due to trapping of water during summer and autumn and entering of wastewater into Zohreh river.

The PH test also indicated that the status of this parameter in all three stations has same range.

The reason for the increase in pollution at the Shiri Station during all studied periods was the increase in consumption of pesticides and fertilizers in the area and accordingly increasing in releasing of a combination of agricultural and industrial wastewater and urban sewage, as a consequence the nutrients, carrying from surface runoff and depositing materials downstream will be increased. Due to frequent droughts and reducing of water flow from water resources, at downstream of this station volume of pollution will be increased and overflow into the station, so the rate of pollution in this area is more intense.

In addition, due to the high temperature at this station in all years and due to the inverse relationship between dissolved oxygen and temperature, the Shiri Station has the lowest amount of dissolved oxygen in all studied years in this research. Obviously, this increase in temperature and the reduction of oxygen will trigger changes in natural and living organisms, start changes in the color of the water, reduce reproduction in animal groups and reduce the ecosystem balance in this area. In addition, the reference to this issue is necessary, unfortunately, the construction of two dam (ASC and Kowsar) will damage the health of the aquatic environment in threat.

According to the results obtained during the 7 years and at most stations, winter season water has better quality due to more precipitation, thus reducing pollutants vice versa at summer season water quality is poorer due to reducing of rainfall.

\section{Discussion}

In this case study, multivariate techniques factor analysis, cluster analysis, and t-test were investigated to determine sources of pollution, the correlation between variables, and the effect of Zohreh dam (Ask Dam) on the water quality.

Major contamination of the Zohreh river is related to agricultural wastes entering the Zohreh river. The river is also of great importance to agriculture, which encounters a variety of natural and artificial sources of pollution along its pathway.

Other sources of water pollution of the Zohreh river can be noted urban wastewater near the sampling sources. Increasing urbanization and industrial and technological development have not only increased urban water consumption, but also increased environmental pollution. In particular, the problem of water pollution has become more complex during the forthcoming time and the increasing use of various chemicals such as detergents, insecticides, herbicides, various chemical fertilizers, etc., and the drainage of wastewater from local factories mixing with irrigation water.

The health, local welfare and social issues associated with the passageway of this important waterway, for example, the air and water health in the city of Hendijan significantly depends on the clarity and health of Zoherh river.

In the past, because the extension and density of incoming waste were not exceeded from the self-restorative and self-purifying proses of water; these issues were not problematic, but nowadays, due to decrease in water flow, the river self-restoring has fewer effects on water quality so river is become contaminated for about at last 6 month of year. The droughts and dehydration have plunged the banks of the Zohreh river. The waters of the Zohre river have already collapsed sharply so that in some places it has been inhabited by coarse fish and insects.

The sharp decline in the water of the Zohreh river made the proper beaches for restoring places for the accumulation of insects and Tobifix larva and red worms.

\section{Conclusion}

This conclusion showed that many of the water quality parameters at the studied stations in the summer are due to evaporation, rainfall shortage, and the total decrease in discharge the river has a worse condition. Also showed that seasons and weather conditions have a great impact on water quality.

We concluded that damming and climate changes have drastic effects on vegetation cover, the forests located on

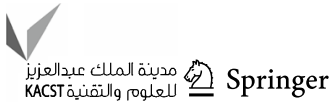


the margins of the main rivers including Zohreh river and extreme effects on waterway system and wetlands.

The forests are growing from the heavy rainforests left in the Mesopotamian area, which every two to three years sprinkled with irrigation rivers. But from last 10 years to now, due to climate change, damming, water control, there was no flood to irrigate the forests. Unfortunately, these forests are drying up and this process has also worsened the burnout of the fires. Meanwhile, in the past 10 years, metrological data show that we have faced drought for seven years during our investigation period. The Houralazim and Shadegan wetlands, which are two of the country's largest wetlands, also main rivers margins flood plans wetlands, have not entered the water hatch or rarely entered since the Maroun and Karkheh dam had been constructed. As a result, these two large international wetlands have dried up. Drying of wetlands and forests can also be effective in economic, social, and climatic conditions and intensification of the regressive phenomenon. Long lasting war at adjacent countries, damming and climate change, causes drying of vegetation cover, forests, and wetlands in these countries, at the consequence of this phenomes aerosols and dust storm have been one of the environmental catastrophe for western parts of the country since recent decades. The dust storm has caused significant damage to the agricultural trade system. The dust of recent decade has exposed a large part of the fields to destruction, and if we do not think about it, we must see a billion damage to agricultural fields."

These days, if we moisten the fields, it is still not useful because the dust is directly seated on the leaf and stem of the plant, and with a disturbance in the respiratory system of the plant, it has a very destructive effect on the plant. The recent dust has destroyed significant percent of the agricultural production in Khuzestan. The major agricultural products damaged in the cities were cereals, nuts, vegetables, citrus fruits, citrus fruits, and forage and this negative effect is different in different agricultural products. Considering that the recent year's dust concentrations occasionally are 60 times more than the standard of dust particles in the air. The intensity of dust and rising concentration of this phenomenon, in addition to air pollution in the Khuzestan cities, intensified the phenomenon of drought and low rainfall. This circumstance has stimulated the vast immigration of people lives in these parts of the country. The dust storm has the negative effect on the health of all living creatures as well as water quality that is essential for a healthfulness and security of life. The information on the effects of water quality related to climate change is inadequate, especially in relation to aquatic ecosystems and ground and surface water, including their social and economic dimensions. Finally, the current tools to facilitate the integrated assessment of compliance and justification options in different parts of the water depending on the amount of water needed. It turns out that rising water crisis is due to climate change in the Zohreh river is more than twice as high as water consumption. In years when runoff is reduced, there is a significant reduction in the quality of water resources. It seems that changes in quantity and quality of water due to climate change will reduce food security and increase the vulnerability of poor rural farmers, especially in the arid areas of the Zohre River Basin.

The efficiency of integrated water resources management provides an important framework for achieving adaptation measures in socio-economic, environmental and administrative systems. For efficiency, integrated approaches should be conducted at appropriate scales.

Water saving in the reservoir dams obviously affects strategies such as energy, health, food security, and nature conservation.

Therefore, the assessment of the implementation and adjustment options should be carried out in several waterrelated departments, so that adaptation strategy should be designed for development, environmental and health policies. Iranians have a brilliant history in water systems management, no doubt, they will pay more attention to the environment and will find numerous solution for this problem with help of adjacent country and all of the authorities and scientist in water planning sector. Water can be managed with changes in our attitude with water, and living style, our cultivation procedures, such as reforming the crop pattern, farmland quota, and supplying water to the industry and agriculture from recycling and reusing of water and genuine in retention of water from precipitation.

\section{Financial Disclosure statement}

This paper is part of Saideh khaffaf Roudy theses for revising M.Sc. in Environmental Science, in Environmental Science Department at Shahied Rajaee Teacher Training University, and is part of plan entitled "Water crises in Iran" is carrying out by first author: Jalal Valiallahi in this University and the authors received no specific funding for above mentioned theses.

\section{Compliance with ethical standards}

Conflict of interest For this article, there is no conflict of ethical standards.

Open Access This article is licensed under a Creative Commons Attribution 4.0 International License, which permits use, sharing, adaptation, distribution and reproduction in any medium or format, as long as you give appropriate credit to the original author(s) and the source, provide a link to the Creative Commons licence, and indicate if changes were made. The images or other third party material in this article are included in the article's Creative Commons licence, unless indicated 
otherwise in a credit line to the material. If material is not included in the article's Creative Commons licence and your intended use is not permitted by statutory regulation or exceeds the permitted use, you will need to obtain permission directly from the copyright holder. To view a copy of this licence, visit http://creativecommons.org/licenses/by/4.0/.

\section{References}

Bates BC, Kundzewicz ZW, Wu S, Palutikof JP (eds) (2008) Climate change and water. Technical paper of the intergovernmental panel on climate change, IPCC secretariat, Geneva, 210 pp. 2008, Intergovernmental panel on climate change, ISBN: 978-92-9169-123-4.

Diana S (1999) Principal component analysis vs. exploratory factor analysis. University of Northern Colorado, SUGI 30, Paper 203. http://www2.sas.com/proceedings/sugi30/203-30.pdf

Han S, Kim E, Kim S (2009) The water quality management in the Nakdong river watershed using multivariate statistical techniques. KSCE J Civ Eng 13(2):97-105. https://doi.org/10.1007/ s12205-009-0097-5

Iscen CF, Emiroglu Ö, Ilhan S et al (2008) Application of multivariate statistical techniques in the assessment of surface water quality in Uluabat Lake, Turkey. Environ Monit Assess 144:269-276

Manshouri M, Ahmadisharaf E, Alamdari N (2011) Qualitative study of Zohreh river water using QUAL2K model. Conference paper . August 2011, Doi: https://doi.org/10.13140/RG.2.1.2032.3043, https://www.researchgate.net/publication/237098981

Ouyang Y (2005) Evaluation of river water quality monitoring stations by principal component analysis. Water Res 39(12):2621-2635

Shrestha S, Kazama F (2007) Assessment of surface water quality using multivariate statistical techniques: a case study of the Fuji river basin. Japan. Environ Model Softw 22(4):464-75.
Shtangeeva I, Alber D, Bukalis G et al (2009) Multivariate statistical analysis of nutrients and trace elements in plants and soil from northwestern Russia. Plant Soil 322:219-228

Singh K, Malika A, Sinha S (2005) Water quality assessment and apportionment of pollution sources of Gomti river (India) using multivariate statistical techniques-a case study. Anal Chim Acta 538:355-374

Varol M, Sen B (2009) Assessment of surface water quality using multivariate statistical techniques: a case study of Behrimaz Stream. Turkey. Environ Monit Assess 159(1-4):543-53. https://doi.org/ 10.1007/s10661-008-0650-6

Wang X, Lu Y, He G et al (2007) Multivariate analysis of interactions between phytoplankton biomass and environmental variablesin Taihu Lake, China. Environ Monit Assess 133:243-253

Wanga X, Homerb M, Dyerb SD et al (2005) A river water qualitymodel integrated with a web-based geographic information system. J Environ Manag 75(3):219-228

Yidanaa SM, Ophoria D, Banoeng-Yakubo B (2008) A multivariatestatistical analysis of surface water chemistry data-the Ankobra Basin, Ghana. J Environ Manag 86(1):80-87

Zhang Q, Li Z, Zeng G et al (2009) Assessment of surface water quality using multivariate statistical techniques in red soil hilly region: a case study of Xiangjiang watershed. China. Environ Monit Assess. 152:123. https://doi.org/10.1007/s10661-008-0301-y

Zhang Y, Guo F, Meng W et al (2009) Water quality assessment and source identification of Daliao river basin using multivariate statistical methods. Environ Monit Assess 152:105-121

Publisher's Note Springer Nature remains neutral with regard to jurisdictional claims in published maps and institutional affiliations. 